\title{
Risk factors for recurrent emergency department visits for asthma
}

\author{
Robert E Dales, Irwin Schweitzer, Pauline Kerr, Luce Gougeon, Robert Rivington, \\ Joan Draper
}

\begin{abstract}
Background - Patients presenting with asthma to emergency departments have lost control of their disease, have significant airways obstruction, and frequently require admission to hospital. Although even one visit is not desirable, there is a more disturbing subgroup who repeatedly visit the emergency department.

Methods - To investigate the reasons for multiple emergency visits, a questionnaire was given to 448 consecutive patients presenting to the two largest adult emergency departments in Ottawa, Canada between November 1989 and April 1991. Within this cohort, those who had made at least three visits in the past year were compared with controls (only one visit in the past year). Results - Although inhaled corticosteroid use increased with multiple visits (indicating increased asthma severity), only $60 \%$ of those visiting at least three times in the past year were taking inhaled corticosteroids. Chronic undermedication relative to disease severity was apparent among the cases. The number of visits was associated with nocturnal asthma on a regular basis, work and school absenteeism, frequent visits to their regular physician, and frequent admissions to hospital. Visits were not related to psychological health, environmental allergens/irritants, or lack of perceived asthma severity.
\end{abstract}

Conclusions - The recommendations of current asthma guidelines are not reaching these patients. The issue of translating guidelines from paper to practice must be addressed before highly effective medications can have an important impact on the frequency of emergency department visits.

(Thorax 1995;50:520-524)

Keywords: asthma, drug therapy, health behaviour, emergency medical services.

The prevalence of asthma among adults is about $5 \%$ according to questionnaire surveys in Canada, the United States, and France. ${ }^{1-5}$ Asthma accounts for 200-250 hospital admissions and approximately 1.7 deaths per 100000 population. ${ }^{67}$ Emergency visits also reflect morbidity. Severe airways obstruction is often present, ${ }^{89}$ most hospital admissions are through the emergency department, and emergency visits may be a risk factor for mortality. ${ }^{10}$ With the highly effective asthma medications currently available, it is unclear why emergency visits occur. In an earlier study we documented chronically poor management and control pre- $\vec{\circ}$ ceding emergency visits. ${ }^{11}$ Of patients requiring emergency care for asthma, 25\% habitually experienced symptoms every second night. $\overrightarrow{\vec{x}}$ This descriptive study, without a control group,,$x$ could not assess risk factors for emergency. visits. Especially troublesome are patients who of frequently use the emergency services for 0 asthma. Little is known about the char-음 acteristics of these individuals who frequentlylose control of their asthma.

To better understand this high morbidity group, a study was undertaken to investigate $\vec{e}$ the potential risk factors for asthma patients. making frequent visits to the emergency de-? partment. Within this cohort cases with at least three visits in the past year were compared witho controls (only one visit in the past year). Theö generalisability of clinical studies performed $\stackrel{\mathbb{}}{\mathcal{Q}}$ outside the clinical population studied is often $\overrightarrow{\hat{O}}$ uncertain and rarely tested. This issue was 3 addressed in the present study by comparing the clinical results, where possible, with those based on a provincial health survey. Hopefully, a better understanding of patients who make frequent visits to emergency departments will ${ }_{\sigma}^{\times}$ contribute to reducing asthma morbidity and 3 . health care costs.

\section{Methods}

STUDY GROUP

Between 18 November 1989 and 30 April 1991 , self-administered questionnaires were distributed by respiratory therapists to patients $\tilde{D}$ presenting with an exacerbation of asthma at $\tilde{\omega}$ the emergency department of the Ottawa Gen? eral Hospital and by nurses or clerks to patients presenting at the Ottawa Civic Hospital. To be eligible, the principal diagnosis of asthma had to appear on the emergency department chart ${ }_{0}^{\circ}$ and inhaled bronchodilators had to be administered. Patients presenting for other $\frac{}{\mathbb{D}}$ reasons but with a history of asthma were $\frac{\varrho}{\sigma}$ excluded, as were those with asthma who came for repeat prescriptions but who were noto treated in the emergency department. Those who were willing but temporarily too distressed $\frac{0}{2}$ to participate were followed up either at home? or in hospital. For patients with more than one recorded visit during the period of study information from the initial questionnaire was used for analysis. 
Table 1 Sociodemographic data and psychological status of subjects assessed by frequency of visits to emergency department

\begin{tabular}{|c|c|c|c|}
\hline & \multicolumn{2}{|c|}{ No. of visits in past year } & \multirow{2}{*}{$\begin{array}{l}\text { OR }(95 \% C I) \text { for } \\
\geqslant 3 \text { v } 1 \text { visit }\end{array}$} \\
\hline & $\begin{array}{l}1 \\
(n=199)\end{array}$ & $\begin{array}{l}\geqslant 3 \\
(n=140)\end{array}$ & \\
\hline $\begin{array}{l}\text { Mean (SD) age (years) } \\
\% \text { male } \\
\text { Median GHQ score } \\
\% \text { post-secondary education } \\
\% \text { unemployed }\end{array}$ & $\begin{array}{l}35(14) \\
39 \\
3(n=166) \\
49 \\
8\end{array}$ & $\begin{array}{l}32(15) \\
34 \\
3(n=93) \\
37 \\
10\end{array}$ & $\begin{array}{l}0.8(0.5 \text { to } 1.3) \\
0.6(0.4 \text { to } 1.0) \\
1.3(0.6 \text { to } 2.8)\end{array}$ \\
\hline
\end{tabular}

Psychological status was measured by The General Health Questionnaire (GHQ).

tionnaire have been previously described. ${ }^{11}$ Briefly, this self-administered questionnaire enquired about sociodemographic factors, degree of "usual" asthma control, exposure to allergens and irritants, "usual" medications prescribed, physician follow up, and patient education. Active smoking was defined by the question: "Do you smoke cigarettes?" and passive smoking by: "Are any of the following present in your home ... cigarette smoke?" The General Health Questionnaire (GHQ-30), which is a validated method of screening, was administered by telephone two weeks after the visit to avoid measuring the acute psychological effects of an emergency visit. ${ }^{1213}$

\section{THE ONTARIO HEALTH SURVEY DATA}

The 1990 Ontario Health Survey targeted all Ontario residents of private dwellings. ${ }^{14} \mathrm{~A}$ sample of households was chosen from geographical clusters. One household member was interviewed about all the household members. The overall response rates were $88 \%$ for the interviewer-completed portion and $77 \%$ for a self-completed questionnaire for those at least 12 years of age. To be consistent with the clinical data obtained from adult hospitals, the health survey data were restricted to those with asthma who were at least 16 years of age. The variables in the health survey similar to those in the clinical study were: age, sex, education, employment, number of physician visits, emergency visits and hospital admissions in the past 12 months, cigarette smoking and exposure to environmental tobacco smoke. Whether or not the emergency visits and hospital admissions were because of asthma could not be de- termined from the survey data. For our purposes it is only necessary to assume that the total number of emergency visits by those with asthma is correlated with the number of visits because of asthma. Odds ratios calculated from the clinical study were compared with those from the population study.

\section{DATA ANALYSES}

The prevalence of each subject characteristic was presented for cases (at least three visits in the past 12 months) and for controls (only one visit in the past 12 months). Unadjusted odds ratios $^{15}$ were used to contrast cases with controls on the presence or absence of potential sociodemographic risk factors (age, sex, unemployment, education) and psychological health. These results are presented in table 1 . Confidence intervals ${ }^{15}$ provided estimates of the statistical significance of the odds ratios. Multiple logistic regression ${ }^{16}$ was then used to estimate odds ratios for other potential risk factors (environmental, medication, asthma control, perceptions) while simultaneously controlling for sociodemographic differences between cases and controls. The equations took the following form:

log odds of being a case $=$

$\mathrm{B} 1 \times$ age $+\mathrm{B} 2 \times$ sex $+\mathrm{B} 3 \times$ education $+\mathrm{B} 4 \times$ unemployment $+\mathrm{B} 5 \times$ potential risk factor of interest in tables $2-4$,

where $B$ is the log odds of the coefficient. There was a separate equation for each risk factor of interest.

\section{Results}

Of the 448 patients presenting at the emergency department who completed the questionnaire there were 140 cases and 199 controls. The remainder, not included in the analysis, were those 109 subjects with two visits who are not considered further. As shown in table 1, the study group was predominantly female with an average age of 34 years, most had no education beyond secondary school, and few were unemployed. Cases were slightly more likely than controls to be unemployed, but this difference

Table 2 Asthma management: environmental control and medications by frequency of emergency department visits

\begin{tabular}{|c|c|c|c|}
\hline & \multicolumn{2}{|c|}{ No. of visits in past year } & \multirow{2}{*}{$\begin{array}{l}\text { Adjusted } O R(95 \% C I) \\
\text { for } \geqslant 3 \text { v } 1 \text { visit }\end{array}$} \\
\hline & $\begin{array}{l}1 \\
(n=199)\end{array}$ & $\geqslant 3$ & \\
\hline $\begin{array}{l}\text { Environmental factors (\%) } \\
\text { Pets } \\
\text { Active smoking } \\
\text { Passive smoking } \\
\text { Bedroom carpets } \\
\text { Unsealed mattress } \\
\text { Workplace triggers }\end{array}$ & $\begin{array}{l}49 \\
30 \\
41 \\
66 \\
94 \\
51\end{array}$ & $\begin{array}{l}47 \\
25 \\
49 \\
67 \\
91 \\
59\end{array}$ & $\begin{array}{l}0.9(0.6 \text { to } 1.4) \\
0.7(0.4 \text { to } 1.1) \\
1.0(0.6 \text { to } 1.6) \\
1.1(0.7 \text { to } 1.7) \\
0.7(0.3 \text { to } 1.6) \\
1.4(0.8 \text { to } 2.4)\end{array}$ \\
\hline $\begin{array}{l}\text { Medications (\%) } \\
\text { Beta agonist only } \\
\text { Inhaled steroid } \\
\text { Oral steroids }\end{array}$ & $\begin{array}{r}44 \\
35 \\
9\end{array}$ & $\begin{array}{l}15 \\
60 \\
27\end{array}$ & $\begin{array}{l}0.2(0.1 \text { to } 0.4) \\
3.7(2.2 \text { to } 6.0) \\
4.6(2.4 \text { to } 8.9)\end{array}$ \\
\hline $\begin{array}{l}\text { Physician follow up } \\
\text { Visits to regular physician ( } \%>5 \text { visits/year) }\end{array}$ & 20 & 46 & $3.7(1.9$ to 7.0$)$ \\
\hline
\end{tabular}


Table 3 Indicators of asthma control by frequency of emergency department visits

\begin{tabular}{|c|c|c|c|}
\hline & \multicolumn{2}{|c|}{ No. of visits in past year } & \multirow{2}{*}{$\begin{array}{l}\text { Adjusted } O R(95 \% C I) \\
\text { for } \geqslant 3 \text { v } 1 \text { visit }\end{array}$} \\
\hline & $\begin{array}{l}1 \\
(n=199)\end{array}$ & $\begin{array}{l}\geqslant 3 \\
(n=140)\end{array}$ & \\
\hline $\begin{array}{l}\text { Sleep disturbed ( } \% \geqslant 7 \text { days } / \text { month) } \\
\text { Work/school absenteeism }(\% \geqslant 9 \text { days/year) } \\
\text { Socialisation affected }(\% \geqslant 9 \text { days/year) } \\
\text { Hospitalisations }(\% \geqslant 2 \text { in past year) }\end{array}$ & $\begin{array}{r}27 \\
18 \\
20 \\
2\end{array}$ & $\begin{array}{l}48 \\
53 \\
46 \\
30\end{array}$ & $\begin{array}{r}2.4(1.5 \text { to } 4 \cdot 0) \\
4.3(2 \cdot 6 \text { to } 7 \cdot 7) \\
3.0(1.7 \text { to } 5 \cdot 2) \\
35.2(10 \text { to } 124)\end{array}$ \\
\hline
\end{tabular}

Odds ratios were adjusted for age, sex, education, and unemployment.

Table 4 Perception of asthma severity by frequency of emergency visits

\begin{tabular}{|c|c|c|c|}
\hline & \multicolumn{2}{|c|}{ No. of visits in past year } & \multirow{2}{*}{$\begin{array}{l}\text { Adjusted } O R(95 \% C I) \\
\text { for } \geqslant 3 \text { v } 1 \text { visit }\end{array}$} \\
\hline & $\begin{array}{l}1 \\
(n=199)\end{array}$ & $\begin{array}{l}\geqslant 3 \\
(n=140)\end{array}$ & \\
\hline $\begin{array}{l}\% \text { perceiving their asthma as very serious } \\
\% \text { perceiving a future attack very likely } \\
\% \text { delaying emergency visit }>5 \text { days } \\
\% \text { with severe dyspnoea on arrival } \\
\% \text { with } \mathrm{FEV}_{1} \text { on arrival }<30 \%\end{array}$ & $\begin{array}{r}16 \\
37 \\
7 \\
53 \\
26\end{array}$ & $\begin{array}{r}31 \\
61 \\
9 \\
51 \\
36\end{array}$ & $\begin{array}{l}2.7(1.4 \text { to } 5.3) \\
2.8(1.6 \text { to } 4.8) \\
1.6(0.7 \text { to } 3.6) \\
1.0(0.6 \text { to } 1.5) \\
1.4(0.4 \text { to } 1.4)\end{array}$ \\
\hline
\end{tabular}

did not reach conventional levels of statistical significance $(p>0.05)$. Sample sizes for the General Health Questionnaire were reduced because of difficulty in reaching subjects by telephone two weeks after the visit to the emergency department. However, among 93 cases and 166 controls there were no differences in psychological health as indicated by the median, 25 th, or 75 th centile values.

Table 2 describes asthma management including environmental control, medications, and physician follow up. Environmental control measures were largely inadequate and almost half had furry or feathered pets at home and were exposed to environmental tobacco smoke. Dust control measures were infrequent, with fewer than $10 \%$ having sealed their mattress from dust. Apart from the home environment, more than one third believed that their workplace exacerbated their asthma. However, there was no association between environmental triggers/inducers and increasing visits when controlled for age, sex, unemployment, and education. Although these factors may have contributed to poor asthma control, their presence did not help to explain the difference between those who visited more and those who visited less frequently.

About one third of the study sample were prescribed only $\beta$ agonists and less than half inhaled corticosteroids. Although the frequency of visits to the emergency department was associated with increased medication (reflecting increased asthma severity), only $60 \%$ of those making at least three visits in the last 12 months were prescribed inhaled corticosteroids.

Interestingly, the frequency of visits to the subject's regular physician was positively associated with multiple emergency visits $(\mathrm{OR}=$ $3.7 ; 95 \%$ CI 1.9 to $7 \cdot 0$ ). Patients were not simply substituting the emergency department for an ambulatory clinic setting. Furthermore, close follow up did not guarantee appropriate asthma treatment and control; of those frequent visitors to the emergency department who also saw their usual physician more than five times yearly, $29 \%$ were not prescribed inhaled corticosteroids (not shown).

Poor control and disability from asthma (table 3) were commonplace, with one third of all patients awakening from sleep at least seven days each month. Disability was strongly and consistently associated with multiple visits. $\frac{0}{8}$ Odds ratios ranged between 2.4 and 4.3 for the following variables: interference with sleep, $\overrightarrow{\overrightarrow{0}}$ work, school, and social activities. Patients who presented frequently to the emergency department were also much more likely to have been previously admitted to hospital ( $\mathrm{OR}=35$; $\overrightarrow{\text { 을 }}$ 95\% CI 10 to 124). Again there was evidence that medication was inadequate; of those with $\dot{-}$ frequent sleep disturbance $16 \%$ were taking 3 only $\beta$ agonists, and ony $50 \%$ were takingo inhaled corticosteroids (not shown). Of those $₹$ with increased absence from work, $13 \%$ were응 taking only $\beta$ agonists and $53 \%$ inhaled cortico- $-\frac{7}{0}$ steroids (not shown).

Appropriately, patients who presented fre- N quently at the emergency department were $N$ more likely to recognise the increased severity of their asthma (table 4). The odds ratios for ${ }_{\sigma}^{\omega}$ rating their asthma as very serious was $2 \cdot 7<$ (95\% CI 1.4 to $5 \cdot 3)$, and for rating a future attack as very likely was $2 \cdot 8(95 \%$ CI $1 \cdot 6 \stackrel{\text { \% }}{?}$ to 4.8 ). There was no association with the 0 frequency of visits and either symptom severity or $\mathrm{FEV}_{1}$ on arrival. This indicates that frequento visits were not simply a result of using a lower $\stackrel{\circ}{\circ}$ threshold of asthma severity to prompt an emergency visit.

The Ontario Health Survey representedo 331722 subjects with asthma over 16 years of age, of whom $36 \%$ stated that they had visited? an emergency department at least once in the past 12 months. Risk ratios derived from sampling the general population sample of Ontario were, for the most part, similar in direction and magnitude to the results obtained in the clinical sample (table 5). The emergency department study did not detect a significant effect of tobacco smoke on the number of 
Table 5 Odds ratios derived from The Ontario Health Survey data

\begin{tabular}{lc}
\hline Subject characteristic & $\begin{array}{l}\text { Unadjusted odds ratios }(95 \% \text { CI) for } \geqslant 3 v 1 \\
\text { emergency visits in past year }\end{array}$ \\
\hline Sex (\% male) & $1 \cdot 5(0 \cdot 9$ to $2 \cdot 5)$ \\
$\%$ post-secondary education & $0 \cdot 5(0 \cdot 3$ to $0 \cdot 9)$ \\
$\%$ employed & $0 \cdot 6(0 \cdot 4$ to $1 \cdot 0)$ \\
$\%$ active smoking & $1 \cdot 6(1 \cdot 0$ to $2 \cdot 4)$ \\
$\%$ passive smoking & $2 \cdot 0(1 \cdot 3$ to $3 \cdot 3)$ \\
$\%>5$ visits/year to physician & $7 \cdot 4(4 \cdot 0$ to $13 \cdot 6)$ \\
$\% \geqslant 2$ hospital admissions/year & $19 \cdot 0(8 \cdot 7$ to $41 \cdot 5)$
\end{tabular}

Of those $>16$ years, 63865 reported one emergency visit in the past 12 months (controls) and 27592 reported at least three visits.

visits, whereas the population survey detected a detrimental effect of both active smoking (OR 1.6) and passive smoking (OR $2 \cdot 0$ ).

\section{Discussion}

In this study emergency department visits were valid indicators of morbidity; $50 \%$ of the patients had severe dyspnoea on arrival and $30 \%$ had an $\mathrm{FEV}_{1}$ of less than $30 \%$ predicted. Multiple visits represented more frequent exacerbations. If the increased frequency had been due to a lower threshold for presentation, the exacerbations would have been less severe. This was not the case. The $\mathrm{FEV}_{1}$ reduction in both groups was similar. Further, the number of emergency visits also correlated with the number of recent hospital admissions.

Inferring causality from a case-control design is always hampered by the possibility of confounding due to unmeasured differences between the two groups which come from two distinct populations. ${ }^{17}$ Garrett et al reported that patients with asthma attending the Middlemore Hospital accident and emergency department in Auckland were "disproportionately of lower socioeconomic class". ${ }^{18}$ Billings et al ${ }^{19}$ demonstrated that hospital utilisation in New York was inversely proportional to income. Brown and $\mathrm{Goel}^{20}$ reported higher use of emergency departments among low income individuals, young adults, and children of single parents. To reduce the possibility of biased results from comparisons between two distinct populations, emergency department users were not contrasted with non-users. Rather, comparisons were made within the same cohort of those using emergency departments. Apart from reducing bias through study design, external validity was assessed by comparing the results, where possible, with those from a provincial population survey. The risk factors for multiple emergency department visits were the same in both the clinical and population survey, with the exception that a small detrimental effect of both active and passive smoking was detected only in the population survey. A significant proportion of all those with asthma in the population visited the emergency department, with $36 \%$ of those over the age of 16 stating that they had made at least one visit to an emergency department within the past 12 months. Thus, observations based on visitors to emergency departments should apply to at least one third of all those with asthma.

Several factors emerged as risk indicators for multiple visits to an emergency department: multiple previous visits to usual physician, dayto-day disability from asthma, previous hospital admissions, and the perception of severe asthma with a high likelihood of future attacks. The only modifiable risk factor identified was undermedication. Although prescription of inhaled corticosteroids was increased among those making frequent visits to the emergency department (probably reflecting increased disease severity), there was undermedication relative to the level of asthma severity; inhaled corticosteroids were not taken by $46 \%$ of these cases who also had $25 \%$ of their nights disturbed by asthma when in their usual state of health. Clearly, these findings are inconsistent with published asthma management guidelines. ${ }^{21-24}$

It has previously been suggested that emergency department use may prevent earlier effective treatment by a general practitioner. ${ }^{25}$ O'Halloran and Heaf recommended that "when treatment at home fails, prompt effective treatment by the general practitioner, which commands the confidence of parents, could reduce the need for emergency hospital treatments" ${ }^{26}$ Unfortunately the present study and a previous study in the UK provide evidence that this ideal situation does not yet exist. The latter study, a survey of general practices, revealed evidence of poor control in a high proportion of asthma cases; $39 \%$ of 7729 patients with asthma were awakened each night by symptoms. ${ }^{27}$ Frequent visits to a physician is no guarantee of good asthma management. Many who were closely followed were poorly controlled and undermedicated in their usual state of health. Of those frequently using both the emergency department and their usual physician (at least six times in the past 12 months), $29 \%$ were not prescribed inhaled corticosteroids. The fact that $46 \%$ of those frequently seen in the emergency department had also seen their "usual" physician at least six times in the past year indicates that patients do not simply substitute the care of the emergency department physician for that of their usual physician. Rather, they are seeking help from all avenues, both from their family physician and the emergency department.

We did not find patients to be psychologically unhealthy or to lack perception of disease severity. Sibbald reported that morbidity was associated with delays in taking appropriate action when confronted with hypothetical crisis situations. ${ }^{28}$ Our results during actual crises revealed a different picture. Those with the greatest morbidity (defined by the most visits to the emergency department) neither delayed longer nor had lower $\mathrm{FEV}_{1}$ levels on arrival. This discrepancy between studies may be due to many methodological differences, but suggests that conclusions based on hypothetical situations need to be validated against real life situations.

Our results suggest the presence of a potentially modifiable risk factor for asthma exacerbations requiring emergency care - that is, moderate to severe asthma chronically under poor control. Exposure to any asthma trigger probably becomes the "last straw". The iden- 
tification and relative importance of risk factors for loss of asthma control has important implications for asthma education and management programmes which are often labour intensive and "comprehensive" in nature. Bailey et al observed that "it was difficult to balance the goal of providing our patients the information they needed with the goal of avoiding the dilutional effect of too much information" ${ }^{29}$ Simply increasing the use of inhaled corticosteroids relative to disease severity has been shown to reduce exacerbations and chronic disability. ${ }^{30}$ The results of the present study demonstrate that undermedication is an important issue, responsible for an increased need for emergency services. Asthma education programmes are patient centred and infrequently include the physician. ${ }^{31}$ Without changing the physician's behaviour prescribing will not improve, undermedication will continue, and patient education will have a limited potential to improve disability. Arguably one of the best studies of an asthma education programme - that of Wilson et $a l^{32}$ - demonstrated significant improvements in symptoms, inhaler technique, and environmental control. However, medications did not change and there were no significant changes in use of medical care for acute exacerbations, the frequency of which were approximately two per year in the follow up period. In contrast, the management programme of Mayo et $a l^{33}$ resulted in a fourfold increase in inhaled corticosteroids and a $2-3$ fold reduction in hospital day use.

The Canadian consensus report on asthma management is alone in recommending that a visit to an emergency department should prompt referral to an asthma specialist. ${ }^{21}$ The implicit assumption of better management and reduced disability is supported by the differences in outcomes found between patients admitted to hospital wards with and without a special interest in respiratory medicine. ${ }^{34}$ Our results support the recommendation that emergency physicians, as part of their care, should arrange follow up with asthma specialists to optimise the management of patients who frequently use the emergency department. Simply treating asthma urgently and returning patients to "usual care" will also return them to their pre-existing state of poor control, frequent exacerbations, and emergency department utilisation.

We would like to thank Dr Vivek Goel at The Institute For Clinical Evaluative Sciences, North York, Canada for critically appraising the manuscript.

1 Dekker C, Dales RE, Bartlett S, Brunekreef B, Zwanenburg $\mathrm{H}$. Childhood asthma and the indoor environment. Chest 1991;100:922-6.

2 Dales RE, Burnett R, Zwanenburg $H$. Adverse health effects among adults exposed to home dampness and moulds. Am Rev Respir Dis 1991;143:505-9.

3 Dodge RR, Burrows $B$. The prevalence and incidence of asthma and asthma-like symptoms in a general population asthma and asthma-like symptoms in a general

4 McWhorter WP, Polis MA, Kaslow RA. Occurrence, pre- dictors, and consequences of adult asthma in NHANESI and follow-up survey. Am Rev Respir Dis 1989;139:721-4.

5 Perdrizet S, Neukirch F, Cooreman J, Liard R. Prevalence of asthma in adolescents in various parts of France and its relationship to respiratory allergic manifestations. Chest 1987;91(Suppl):104-6S.

6 Weiss KB. Seasonal trends in US asthma hospitalizations and mortality. $\mathcal{F} A M A$ 1990;263:2323-8.

7 Benatar SR. Medical progress. Fatal asthma. $N$ Engl 7 Med 1986;314:423-8.

8 Rebuck AS, Chapman KR, Abboud R, Pare PD, Kreisman $\mathrm{H}$, Wolkove $\mathrm{N}$, et al. Nebulized anticholinergic and sympathomimetic treatment of asthma and chronic obstructive airways disease in the emergency room. $A m \mathcal{F}$ Med 1987, 82:59-64.

9 Nowak RM, Pensler MI, Sarkar DD, Anderson JA, Kvale PA, Ortiz AE, et al. Comparison of peak expiratory flow and $\mathrm{FEV}_{1}$ admission criteria for acute bronchial asthma. Ann Emerg Med 1982;11:64-9.

10 Rhea HH, Scragg R, Jackson R, Beaglehole R, Fenwick J, Sutherland $\mathrm{D}$. A case control study of deaths from asthma. Thorax 1986;41:833-9.

11 Dales RE, Kerr PE, Schweitzer I, Reesor K, Gougeon L. Asthma management preceding an emergency department visit. Arch Intern Med 1992;152:2041-4.

12 Goldberg D. Manual of the General Health Questionnaire. Windsor: National Foundation for Education Research, 1978.

13 McDowell I, Newell C. Measuring health: a guide to rating scales and questionnaires. New York: Oxford University Press, 1987:139-49.

14 Ontario Health Survey 1990 user's guide, volume 1: documentation. The OHS 1990 Information, Planning and Evaluation Branch, Ministry of Health, Toronto, Ontario.

15 Fleiss JL. Statistical methods for rates and proportions. 2nd edn. New York: John Wiley and Sons, 1981.

16 Cary NC. SAS user's guide: statistics. Version 5. SAS Institute Inc, 1985:171-354.

17 Fletcher RH, Fletcher SW, Wagner EH (eds). Clinical epidemiology: the essentials. 2nd edn. Baltimore: Williams and Wilkins, 1988.

18 Garrett JE, Mulder J, Wong-Toi H. Characteristics of asthmatics using an urban accident and emergency department. NZ Med f 1988;101:359-61.

19 Billings J, Zeitel L, Lukomnik J, Carey TS, Blank AE Newman L. Datawatch: impact of socioeconomic status on hospital use in New York City. Health Affairs 1993; Spring:162-73.

20 Brown EM, Goel V. Factors related to emergency department utilization: results from the Ontario Health Survey, 1990. utilization: results from the Ontario Health Survey, 1990. uative Sciences in Ontario, North York, Ontario, Canada 1993.

21 Hargreaves FE, Dolovich J, Newhouse MT. The assessment and treatment of asthma: a conference report. F Allergy Clin Immunol 1990;85:1098-111.

22 Sheffer AL (chairman). Expert panel report: guidelines for the diagnosis and management of asthma. National Asthma Education Program. Office of Prevention, Education, and Education Program. Office of Prevention, Education, and tional Institutes of Health, Bethesda, Maryland 20892. Publication No. 91-3042, August 1991.

23 Sheffer AL (chairman). International consensus report on diagnosis and treatment of asthma. National Heart, Lung, and Blood Institute. National Institutes of Health, Bethesda, Maryland 20892. Publication No. 92-3091, June 1992.

24 British Thoracic Society. Guidelines on the management of asthma. Thorax 1993;48(Suppl):S1-24.

25 Garrett JE, Mulder J, Veale A. Trend in the use of an urban accident and emergency department by asthmatics. $N Z N$ Med f 1988;101:253-5.

26 O'Halloran SM, Heaf DP. Recurrent accident and emergency department attendance for acute asthma in children. Thorax 1989;44:620-6.

27 Turner-Warwick M. Epidemiology of nocturnal asthma. Am f Med 1988;85(Suppl 1B):6-8.

28 Sibbald B. Patient self care in acute asthma. Thorax 1989; 44:97-101.

29 Bailey WC, Richards JM, Manzella BA, Windsor RA, Brooks $\mathbb{D}$ CM, Soong S-J. Promoting self-management in adults with asthma: an overview of the UAB program. Health Educ $Q$ 1987;14:345-55.

30 McCarthy TP, Taylor MD, Richardson PDI. The management of asthma using clinical protocols: Is it cost effective, and does it improve patients' lifestyles. $\mathrm{Br} \mathcal{F} \mathrm{Med}$ Econ 1992;2:13-24.

31 Toelle BG, Peat JK, Salome CM, Craig MM, Bauman AE, Woolcock AJ. Evaluation of a community-based asthma Woolcock AJ. Evaluation of a community-based asthma management program in a population sample of schoo

32 Wilson SR Scamagas P, German DF, Hughes GW, Lulla $\mathrm{S}$, Coss S, et al. A controlled trial of two forms of selfmanagement education for adults with asthma. Am $\mathcal{f}$ Med 1993;94:564-76.

33 Mayo PH, Richman J, Harris HW. Results of a program to reduce admissions for adult asthma. Ann Intern Med 1990; 112:864-71.

34 Bucknall CE, Robertson C, Moran F, Stevenson RD. Differences in hospital asthma management. Lancet 1988; ii:748-50. 